\begin{tabular}{|c|c|}
\hline Title & A new approach for evaluating the infectivity of noncultivatable enteric viruses without cell culture \\
\hline Author(s) & Tojo, Kazuki; Sano, Daisuke; Miura, Takay uki; Nakagomi, Toy oko; Nakagomi, O samu; Okabe, Satoshi \\
\hline Citation & $\begin{array}{l}\text { Water Science \& Technology, 67(10), 2236-2240 } \\
\text { https://doi.org/10.2166/wst.2013.114 }\end{array}$ \\
\hline Issue Date & 2013 \\
\hline Doc URL & http:/hdl.handle.net/2115/54103 \\
\hline Rights & $\begin{array}{l}\text { OIWA Publishing 2013. The definitive peer-reviewed and edited version of this article is published in W ater Science \& } \\
\text { Technology V ol } 67 \text { No } 10 \text { pp 2236-2240 } 2013 \text { doi:10.2166/wst.2013.114 and is avail able at www.iwapublishing.com. }\end{array}$ \\
\hline Type & article (author version) \\
\hline File Information & Cap3W ST v4.pdf \\
\hline
\end{tabular}

Instructions for use 


\title{
A new approach for evaluating the infectivity of noncultivatable enteric viruses without cell culture
}

\author{
Kazuki Tojo ${ }^{*}$, Daisuke Sano ${ }^{*}$, Takayuki Miura ${ }^{*}$, Toyoko Nakagomi** ${ }^{* *}$ Osamu Nakagomi** ${ }^{* *}$, and \\ Satoshi Okabe* \\ *Division of Environmental Engineering, Faculty of Engineering, Hokkaido University, North 13, \\ West 8, Sapporo, Hokkaido 060-8628, Japan \\ (E-mail: dsano@eng.hokudai.ac.jp; tmiura312@eng.hokudai.ac.jp; sokabe@eng.hokudai.ac.jp) \\ ${ }^{* *}$ Department of Molecular Microbiology and Immunology, Graduate School of Biomedical \\ Sciences and the Global Center of Excellence, Nagasaki University, 1-12-4 Sakamoto, \\ Nagasaki 852-8523, Japan
}

\begin{abstract}
This study developed a novel approach for evaluating the infectivity of enteric viruses without cell culture. Cumulative carbonyl groups on the viral capsid protein were labeled using biotin hydrazide, and the biotinylated virions were separated using a spin column filled with avidin-immobilized gel. Rotavirus was treated with free chlorine at an initial concentration of $0.3 \mathrm{mg} / \mathrm{L}$ for $3 \mathrm{~min}$, and the $\log$ reduction in the infectious titer was $0.19 \log (\mathrm{SD}=0.05)$. The $\log$ reduction of rotavirus treated with free chlorine at an initial concentration of $0.6 \mathrm{mg} / \mathrm{L}$ for 3 min was $2.6 \log (\mathrm{SD}=0.37)$. No significant reductions in the amplicon copy numbers were observed in these free chlorine-treated samples. The recovery levels of intact virions in the first three fractions after biotin-avidin affinity chromatography were 76,21 , and $2.8 \%$, while those of virions treated with free chlorine at an initial concentration of $0.3 \mathrm{mg} / \mathrm{L}$ for $3 \mathrm{~min}$ were 70,23 , and $5.6 \%$. These results showed that the proposed approach could discriminate a $0.19 \mathrm{log}$ infectivity-reduced population from an intact population, although no reduction in the amplicon copy number was observed. This novel method could be applied to noncultivatable enteric viruses such as human norovirus and sapovirus, and it could be very helpful for evaluating the viral inactivation efficiencies of intervention measures.
\end{abstract}

Keywords:

carbonyl group; disinfection; enteric virus; free chlorine; infectivity; oxidative damage

\section{INTRODUCTION}

Enteric viruses in water cause health problems and are associated with economic losses throughout the world (Akihara et al., 2005; Svraka et al., 2009). Various intervention measures are available for controlling the infectious diseases caused by enteric viruses, including water treatment with oxidants and ultraviolet light (Shannon et al., 2008). However, the presence of noncultivatable viruses, such as human norovirus and sapovirus, and the inability of molecular detection methods to distinguish infectious virions from non-infectious virions (Rodriguez et al., 2009) have hindered the development of an assay for assessing the infectivity loss of enteric viruses because of these intervention procedures.

In this study, we developed a novel approach for investigating the infectivity of noncultivatable enteric viruses without cell culture where cumulative carbonyl groups on the viral capsid protein, which are created by oxidative stresses, were detected. The carbonyl groups on the viral capsid protein were labeled with biotin, and damaged (biotinylated) virions were separated from intact (non-biotinylated) virions using a spin column filled with avidin-immobilized gel. This novel approach allowed us to quantify intact and damaged virions separately by quantitative RT-PCR (qRT-PCR). Our previous study showed that the quantity of carbonyl groups on the capsid proteins of 
human norovirus and astrovirus increased with the free chlorine dose and was correlated to the infectivity loss of human astrovirus (Sano et al., 2010). This approach could be utilized as a general tool for investigating the infectivity loss of enteric viruses if there is a significant correlation between the quantity of carbonyl groups on the viral capsid protein and the infectivity loss, irrespective of the enteric virus species.

Rhesus rotavirus was used as the test virus in this study. Rotavirus was treated with low doses of free chlorine, and the infectivity loss was evaluated using the plaque method. The reduction in the viral amplicon copy number after the free chlorine treatment was also analyzed by qRT-PCR. The free chlorine-treated virions were labeled with biotin hydrazide. The biotinylated virions were trapped using a spin column filled with avidin-immobilized gel. The numbers of untrapped and trapped virions captured by the spin column were quantified separately by qRT-PCR, and the relationship between the carbonylation level and the infectivity loss was investigated. Based on the results of these assays, we discuss the feasibility of our novel approach as a general tool for investigating the infectivity of enteric viruses.

\section{MATERIALS AND METHODS}

\section{Test virus and cells}

Fetal rhesus monkey kidney cells (MA-104) were cultured in Eagle's minimal essential medium (MEM) with Earle's salts containing 10\% (vol/vol) fetal bovine serum, $0.075 \% \mathrm{NaHCO}_{3}, 2 \mathrm{mM}$ L-glutamine, $10 \mathrm{mM}$ nonessential amino acids, $100 \mathrm{mg} / \mathrm{mL}$ penicillin, and $100 \mathrm{U} / \mathrm{mL}$ streptomycin. The cells were grown to a confluent monolayer at $37^{\circ} \mathrm{C}$ with $5 \% \mathrm{CO}_{2}$ in a humidifying incubator. Group A rotavirus was propagated in MA-104 cells for $3-5$ days at $37^{\circ} \mathrm{C}$. The virus stock was prepared using the freeze-thaw method, followed by Triton X-100 extraction and polyethylene glycol precipitation, as described elsewhere (Sano et al., 2010), and stored at $-80^{\circ} \mathrm{C}$ until use. The infectious titer of rotavirus A was assayed using the plaque method with MA-104 cells (O'Mahony et al., 2000). The viral amplicon copy number was quantified using a qRT-PCR assay (Pang et al., 2004).

\section{Free chlorine treatment and biotinylation of virions}

The test virus was treated with free chlorine from sodium hypochlorite (Sigma). The free chlorine concentration was measured using a chlorine and $\mathrm{pH}$ test kit (Macherey-Nagel). A virus stock suspension was diluted with $4 \mathrm{~mL}$ of phosphate-buffered saline (PBS, $\mathrm{pH}=7.4$ ) and the free chlorine concentration was adjusted using $1 \%$ sodium hypochlorite. The virus suspension in PBS was treated with free chlorine at initial concentrations of 0.3 and $0.6 \mathrm{mg} / \mathrm{L}$ for $3 \mathrm{~min}$ at $4^{\circ} \mathrm{C}$ in the dark. As a control, a virus suspension without free chlorine was also incubated under the same conditions.

After incubation and neutralization with sodium thiosulfate solution (Sigma), the virus suspensions were stored at $-20^{\circ} \mathrm{C}$. The virus particles were biotinylated as follows. First, $25 \mu \mathrm{L}$ of $50 \mathrm{mM}$ EZ-Link biotin hydrazide (Pierce) in DMSO was added to $1 \mathrm{~mL}$ of virus suspension. Next, the mixture of biotin hydrazide and virus particles was incubated at room temperature for $2 \mathrm{~h}$ with moderate mixing. The mixture was purified using a Zeba Desalt Spin Column (Thermo Scientific) to remove the unreacted biotin hydrazide. The biotinylated virus particles were then stored at $-20^{\circ} \mathrm{C}$ until further analysis.

\section{Separation of biotinylated virions using avidin-immobilized gel}

The biotinylated virions were added to a spin column filled with avidin-immobilized gel (Sigma). After incubation for $15 \mathrm{~min}$, the spin column was centrifuged at $42 \times g$ for $5 \mathrm{~min}$, and the filtrate was recovered (Fraction 1), which contained the untrapped virions. PBS was poured into the spin column. 
The spin column was centrifuged at $42 \times g$ for $5 \mathrm{~min}$, and the filtrate was recovered (Fraction 2). This process was repeated (Fraction 3). Next, $2 \mathrm{mM}$ of biotin in PBS was poured into the spin column to recover the strongly trapped virions. After incubation for $1 \mathrm{~min}$, the spin column was centrifuged at $1,070 \times g$ for $1 \mathrm{~min}$, and the filtrate was recovered (Fraction 4). Finally, glycine buffer $(\mathrm{pH}=2.8)$ was poured into the spin column to denature the avidin molecules. After incubation for $1 \mathrm{~min}$, the spin column was centrifuged at $1,070 \times g$ for $1 \mathrm{~min}$, and the filtrate was recovered (Fraction 5). The biotinylated viral particles, including inactivated particles, were present in the latter four fractions (Fractions 2-5), depending on their level of biotinylation. The amplicon copy numbers of the viral genome in each fraction were quantified by qRT-PCR (Pang et al., 2004). The spin column approach shown in Fig. 1 allowed us to process at least six samples per hour. In contrast, the conventional approach using avidin-immobilized affinity chromatography requires approximately $3 \mathrm{~h}$ per sample (Sano et al., 2010). Thus, this spin column method was approximately 18 times more efficient than the conventional chromatography approach with regard to the sample processing time.

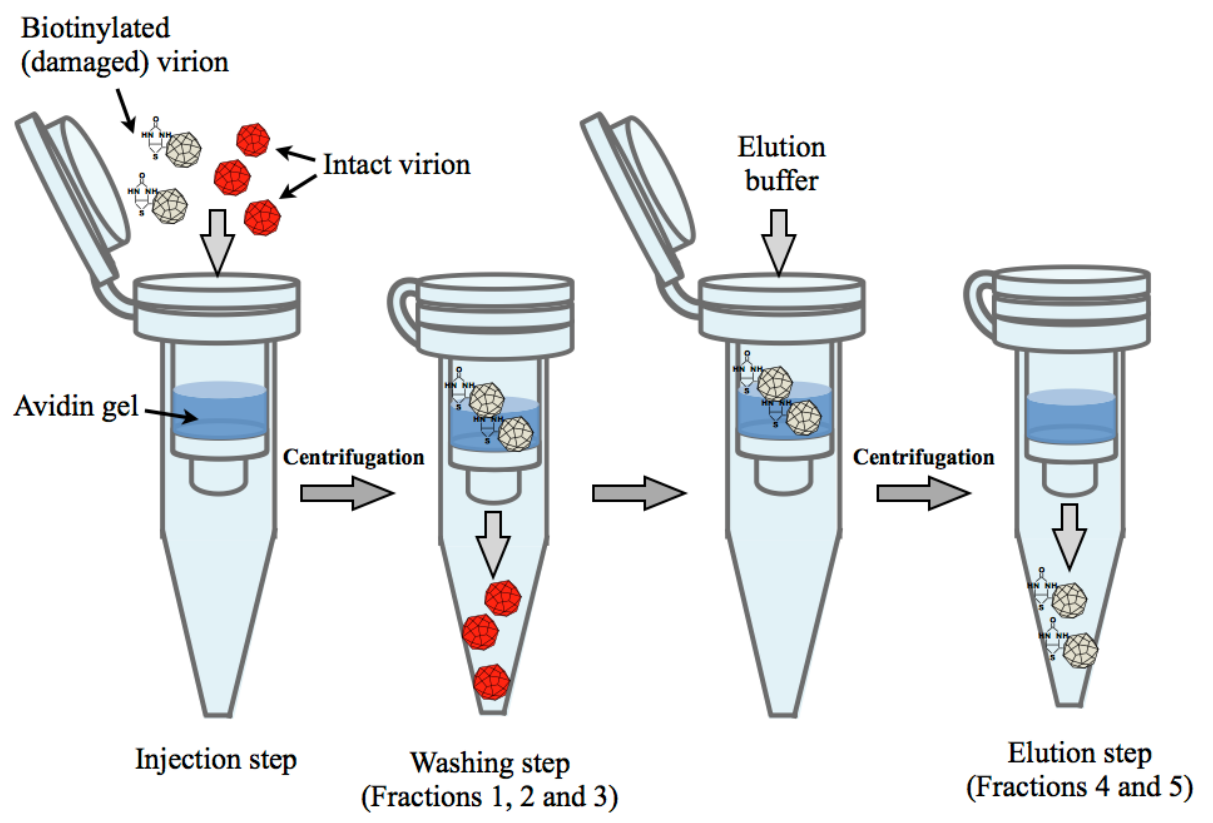

Fig. 1. Illustration of the spin column method used to separate biotinylated virions from intact virions.

\section{RESULTS AND DISCUSSION}

\section{Reduction in the infectivity and amplicon copy numbers of rotaviruses using free chlorine}

Rotavirus was treated with free chlorine at an initial concentration of $0.3 \mathrm{mg} / \mathrm{L}$ for $3 \mathrm{~min}$, and the $\log$ reduction in the infectious titer was $0.19 \log (\mathrm{SD}=0.05)$. The $\log$ reduction after treatment with free chlorine at an initial concentration of $0.6 \mathrm{mg} / \mathrm{L}$ for $3 \mathrm{~min}$ was $2.6 \log (\mathrm{SD}=0.37)$ (Fig. 2). No significant reductions in the amplicon copy numbers were observed in the free chlorine-treated samples. These results indicated that the conventional qRT-PCR assay could not distinguish the infectious titers of these two populations of rotavirus treated with different free chlorine concentrations. 


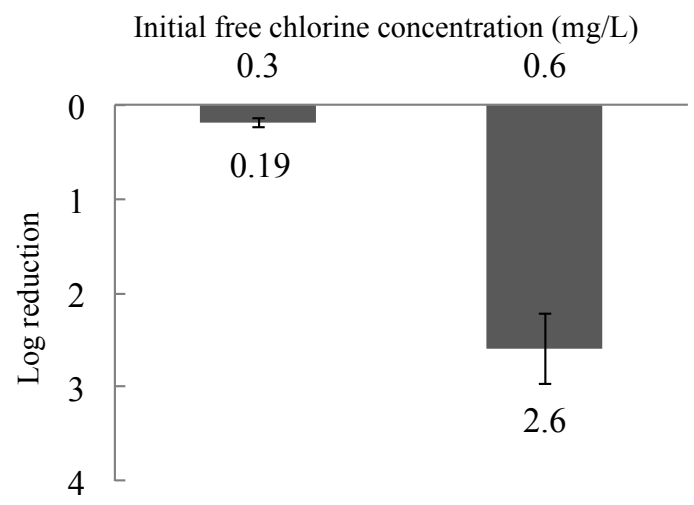

Fig. 2. Log reduction in the rotavirus infectivity after free chlorine treatment. Error bar indicates standard deviation in triplicates.

\section{Separation of biotinylated virions using an avidin affinity spin column}

The recovery levels of intact virions (negative control population without the free chlorine treatment) from Fractions 1, 2, 3, 4, and 5 were 76, 21, 2.8, 0.3, and 0.0\%, respectively (Fig. 3, white bar). The $0.19 \mathrm{log}$ infectivity-reduced population of rotavirus yielded slightly different results, especially in Fractions 1, 2 and 3 where the viral RNA recovery levels were 70, 23, and 5.6\% (Fig. 3, light gray bar). A statistically significant difference was observed in the recovery level in Fraction 3 (Student's t-test: $P<0.05$ ). The retention time of viral particles in the spin column filled with avidin-immobilized gel increased by higher amounts of biotin on the viral particle surface; thus, the increased viral RNA recovery in Fraction 3 indicated that the $0.19 \log$ infectivity-reduced population of rotavirus contained more biotinylated virions than the intact population.

Viral RNA recovery was affected further in the $2.6 \mathrm{log}$ infectivity-reduced population where 39,51 , and $9.0 \%$ of the viral RNA was recovered in Fractions 1, 2, and 3, respectively. These results suggest that a higher dose of free chlorine accumulated more carbonyl groups on the viral particle surfaces. Thus, the $0.19 \log$ and $2.6 \log$ infectivity-reduced viral populations could be distinguished, although there were no reductions in the amplicon copy numbers.

It was difficult to determine the infectious titer of rotaviruses in each fraction because of the toxicity of dimethyl sulfoxide, which was used to dissolve biotin hydrazide. However, it was likely that the inactivated viral particles were present in the early fractions because $>98 \%$ of viral particles were recovered in the first three fractions, even with the $2.6 \mathrm{log}$ infectivity-reduced population (Fig. 3). The biotinylated protein molecules were rarely stripped from the spin column in the first three fractions; therefore, it was necessary to consider the size of the virus particles, which are significantly larger than standard protein molecules. Larger biotinylated molecules may have been detached more readily from the avidin gel because of the larger inertia force and torque created when the hydrodynamic shear force was applied to the spin column. This issue will be addressed in a future study.

RT-PCR and its related techniques have shown that various pathogenic viruses cause gastroenteritis via contaminated water (Abbaszadegan et al., 1999), food (Le Guyader et al., 2006), and fomites (Abad et al., 2001; Boone and Gerba, 2007). It has also been shown that noncultivatable viruses such as human norovirus and sapovirus comprise a significant proportion of the enteric viruses that contaminate water environments (Ueki et al., 2005; Hansman et al., 2007; Sano et al., 2011). An important scientific challenge in the field of public health virology is an evaluation of the health risks posed by these noncultivatable viruses in natural environments. RT-PCR assays only capture a very small fraction of the entire viral genome, which is not representative the genome as a whole. The use of surrogate viruses has been a very important approach in this field (Bae and Schwab, 2008), but 
information about the viability of noncultivatable viruses per se will be indispensable for addressing the problems of environmental contamination by noncultivable enteric viruses.

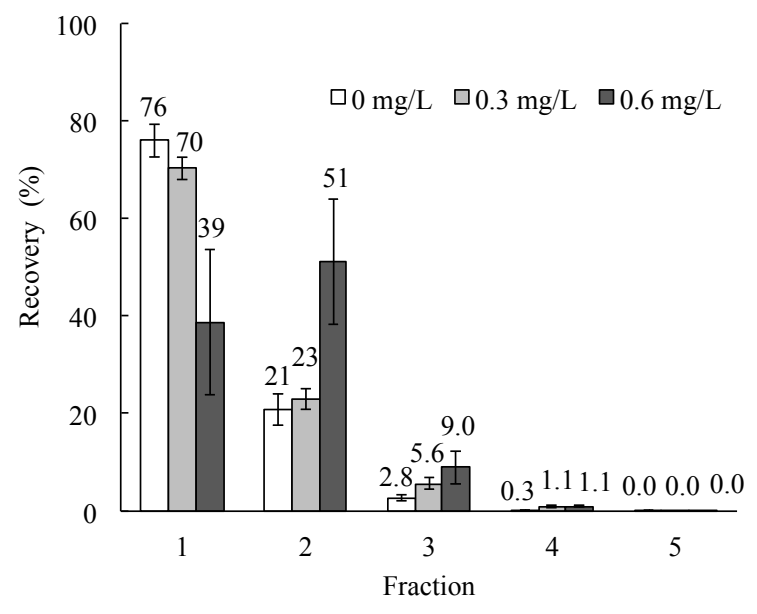

Fig. 3. Recovery of rotavirus RNA from each affinity column fraction. The error bars indicate the standard deviation based on triplicate analyses.

An important aspect of the present study is the ability to determine the viral infectivity reduction level using the proposed method. The variation coefficient value in the plaque method is usually 0.1-0.2. Therefore, an infectivity reduction of $0.1 \mathrm{log}$ is barely detectable, whereas a reduction of $0.2 \mathrm{log}$ could be detected using conventional cell culture-based approaches. In this study, we showed that the 0.19 $\log$ infectivity-reduced population could be discriminated from the intact population, which demonstrated that the ability to detect viral infectivity reduction using our proposed method was equivalent to that of the plaque method.

Impurities are co-concentrated with enteric viruses in environmental water samples, and this might affect the detection of carbonyl groups. Therefore, it will be very important to evaluate the applicability of the proposed method to environmental water samples. Furthermore, it is necessary to determine the maximum level of inactivation that can be identified using the proposed method. The proposed method allowed us to detect a reduction of $2.6 \mathrm{log}$ in the rotavirus infectious titer (Fig. 3), but this was not the maximum level of inactivation that could be detected. It will be necessary to determine the limitations of this method with respect to the inactivation level in a future study.

\section{CONCLUSION}

In this study, we developed a novel approach for investigating the infectivity of noncultivatable enteric viruses where cumulative carbonyl groups on the viral capsid protein, which are created by oxidative stresses, were detected quantitatively by biotinylation and separation using a spin column filled avidin-immobilized gel. This method was capable of detecting a $0.19 \log$ infectivity reduction in a rotavirus population compared with the intact population. This infectivity loss detection level is equivalent to that achieved using the plaque method. The proposed approach could be very helpful for evaluating the inactivation efficiencies of noncultivable enteric viruses after intervention measures.

\section{ACKNOWLEDGMENT}

This work was funded by Core Research for Evolutionary Science and Technology, Japan Science and Technology Agency (JST). 


\section{REFERENCES}

Abad, F. X., Villena, C., Guix, S., Caballero, S., Pintó, R. M. \& Bosch, A. 2001. Potential role of fomites in the vehicular transmission of human astroviruses. Applied and Environmental Microbiology 67(9), 3904-3907.

Abbaszadegan, M., Stewart, P. \& Lechevallier, M. 1999. A strategy for detection of viruses in groundwater by PCR. Applied and Environmental Microbiology 65(2), 444-449.

Akihara, S., Phan, T. G., Nguyen, T. A., Hansman, G., Okitsu, S. \& Ushijima, H. 2005. Existence of multile outbreaks of viral gastroenteritis among infants in a day care center in Japan. Archives of Virology 150, 2061-2075.

Bae, J. \& Schwab, K. J. 2008. Evaluation of murine norovirus, feline calicivirus, poliovirus, and MS2 as surrogates for human norovirus in a model of viral persistence in surface water and groundwater. Applied and Environmental Microbiology 74(2), 477-484.

Boone, S. A. \& Gerba, C. P. 2007. Significance of fomites in the spread of respiratory and enteric viral disease. Applied and Environmental Microbiology 73(6), 1687-1696.

Hansman, G. S., Sano, D., Ueki, Y., Imai, T., Oka, T., Katayama, K., Takeda, N. \& Omura, T. 2007. Sapovirus in water, Japan. Emerging Infectious Diseases 13(1), 133-135.

Le Guyader, F. S., Bon, F., DeMedici, D., Parnaudeau, S., Bertone, A., Crudeli, S., Doyle, A., Zidane, M., Suffredini, E., Kohli, E., Maddalo, F., Monini, M., Gallay, A., Pommepuy, M., Pothier, P. \& Ruggeri, F. M. 2006. Detection of multiple noroviruses associated with an international gastroenteritis outbreak linked to oyster consumption. Journal of Clinical Microbiology 44(11), 3878-3882.

O’Mahony, J., O’Donoghue, M., Morgan, J. G. \& Hill, C. 2000. Rotavirus survival and stability in foods as determined by an optimised plaque assay procedure. International Journal of Food Microbiology 61, 177-185.

Pang, X. L., Lee, B., Boroumand, N., Leblanc, B., Preiksaitis, J. K. \& Ip, C. C. Y. 2004. Increased detection of rotavirus using a real time reverse transcription-polymerase chain reaction (RT-PCR) assay in stool specimens from children with diarrhea. Journal of Medical Virology 72, 496-501.

Pecson, B. M., Ackermann, M., \& Kohn, T. 2011. Framework for using quantitative PCR as a nonculture based method to estimate virus infectivity. Environmental Science and Technology 45, 2257-2263.

Rodriguez, R. A., Pepper, I. L. \& Gerba, C. P. 2009. Application of PCR-based methods to assess the infectivity of enteric viruses in environmental samples. Applied and Environmental Microbiology 75(2), 297-307.

Sano, D., Pintó, R. M., Omura, T. \& Bosch, A. 2010. Detection of oxidative damages on viral capsid protein for evaluating structural integrity and infectivity of human norovirus. Environmental Science and Technology 44, 808-812.

Sano, D., Perez-Sautu, U., Guix, S., Pintó, R. M., Miura, T., Okabe, S. \& Bosch, A. 2011. Quantification and genotying of human sapoviruses in the Llobregat river catchment, Span. Applied and Environmental Microbiology 77(3), 1111-1114.

Shannon, M. A., Bohn, P. W., Elimelech, M., Georgiadis, J. G., Marinas, B. J. \& Mayes, A. M. 2008. Science and technology for water purification in the coming decades. Science 452, 301-310.

Svraka, S., van der Veer, B., Duizer, E., Dekkers, J., Koopmans, M. \& Vennema, H. 2009. Novel approach for detection of enteric viruses to enable syndrome surveillance of acute viral gastroenteritis. Journal of Clinical Microbiology 47(6), 1674-1679.

Ueki, Y., Sano, D., Watanabe, T., Akiyama, K. \& Omura, T. 2005. Norovirus pathway in water environment estimated by genetic analysis of strains from patients of gastroenteritis, sewage, treated wastewater, river water and oysters. Water Research 39, 4271-4280. 